Received: 20 December 2017

Accepted: 3 April 2018

Published online: 19 April 2018

ENTIFIC REP

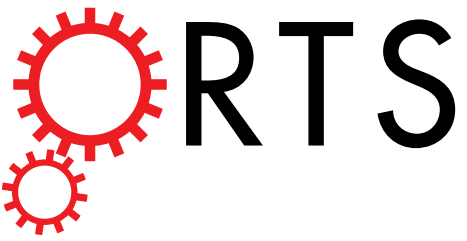

\title{
OPEN
}

\section{Enzyme-catalyzed Ag Growth on Au Nanoparticle-assembled Structure for Highly Sensitive Colorimetric Immunoassay}

\author{
Xuan-Hung Pham $\mathbb{1}^{1}$, Eunil Hahm ${ }^{1}$, Tae Han Kim¹, Hyung-Mo Kim ${ }^{1}$, Sang Hun Lee ${ }^{3}$, \\ Yoon-Sik Lee ${ }^{3}$, Dae Hong Jeong ${ }^{2} \&$ Bong-Hyun Jun ${ }^{1}$
}

We have developed a sensitive colorimetric immunoassay with broad dynamic range using enzymecatalyzed Ag growth on gold nanoparticle (NP)-assembled silica $\left(\mathrm{SiO}_{2} @ \mathrm{Au} @ \mathrm{Ag}\right.$ ). To reduce $\mathrm{Ag}^{+}$ion content and promote Ag growth on the assembled Au NPs, alkaline phosphatase (AP)-based enzymatic amplification was incorporated, which considerably increased the colorimetric read-out. As a model study, sandwich enzyme-linked immunosorbent assay (ELISA) was used to quantify target IgG. The immune complexes capture the Ab-IgG-AP-labeled detection Ab and trigger the enzyme-catalyzed reaction to convert 2-phospho-L-ascorbic acid to ascorbic acid in the presence of the target lgG. Ascorbic acid reduced $\mathrm{Ag}^{+}$to $\mathrm{Ag}$, which formed $\mathrm{Ag}$ shells on the surface of $\mathrm{SiO}_{2} @ \mathrm{Au}$ and enhanced the absorbance of the $\mathrm{SiO}_{2} @ A \mathrm{~A} @ A g$ solution. Plasmonic immunoassay showed a significant linear relationship between absorbance and the logarithm of $\mathrm{IgG}$ concentration in the range of $\mathrm{ca} .7 \times 10^{-13} \mathrm{M}$ to $7 \times 10^{-11} \mathrm{M}$. The detection limit was at $1.4 \times 10^{-13} \mathrm{M}$, which is several hundred folds higher than that of any conventional colorimetric immunoassay. Thus, our novel approach of signal-amplification can be used for highly sensitive in vitro diagnostics and detection of target proteins with the naked eye without using any sophisticated instrument.

Immunological assays in medicine are one of the most prominent analytical techniques for early diagnosis of diseases and monitoring of treatment efficacy. Extensive research efforts have been directed at improving the sensitivity of these methods by combining immunological techniques with various analytical techniques such as surface plasmon resonance ${ }^{1,2}$, quartz crystal microbalance ${ }^{3}$, surface-enhanced Raman spectroscopy ${ }^{4}$, fluorescence spectroscopy ${ }^{5,6}$, electrochemistry ${ }^{7-13}$, chemiluminescence ${ }^{14}$, and colorimetric assay ${ }^{15,16}$. Among these, the enzyme-linked immunosorbent assay (ELISA) is a popular and low-cost colorimetric immunoassay for assaying clinically salient target molecules ${ }^{17-20}$ because of its simplicity and practical applicability, which allows rapid/ direct readout with the naked eye $\mathrm{e}^{21-27}$. However, conventional ELISA is limited to a narrow dynamic range for quantitative detection ${ }^{28}$, with picomolar level detection limit, which renders them incapable of detecting scarce proteins in body fluids or tissues ${ }^{29}$. As a result, methods for enhancing ELISA sensitivity via amplification of enzyme-mediated signals are being actively studied.

Recently, ELISA with ultra-high sensitive nanomaterial-based signal amplification has attracted considerable attention ${ }^{30}$. Since nanomaterials possess features such as catalytic activity, conductivity, and biocompatibility, they can be utilized to accelerate signal transduction and amplification in ELISA. Most importantly, nanoscale materials can function as sensors with resolution of single-molecule detection ${ }^{31}$. Gold nanoparticles (AuNPs) have been widely utilized in bio-analytics due to their superb biocompatibility, and ease of surface modification and preparation ${ }^{32}$. A variety of highly sensitive monodispersed or aggregated AuNP-based immunoassays have been reported ${ }^{15,33-36}$. However, most of these immunoassays cannot precisely quantify the concentration of target molecules because of their narrow linear range of target detection ${ }^{33}$. Therefore, development of highly sensitive and quantitative AuNP-based immunoassays is considerably challenging.

${ }^{1}$ Department of Bioscience and Biotechnology, Konkuk University, Seoul, 143-701, Republic of Korea. ${ }^{2}$ Department of Chemistry Education, Seoul National University, Seoul, 151-742, Republic of Korea. ${ }^{3}$ School of Chemical and Biological Engineering, Seoul National University, Seoul, 151-742, Republic of Korea. Correspondence and requests for materials should be addressed to B.-H.J. (email: bjun@konkuk.ac.kr) 


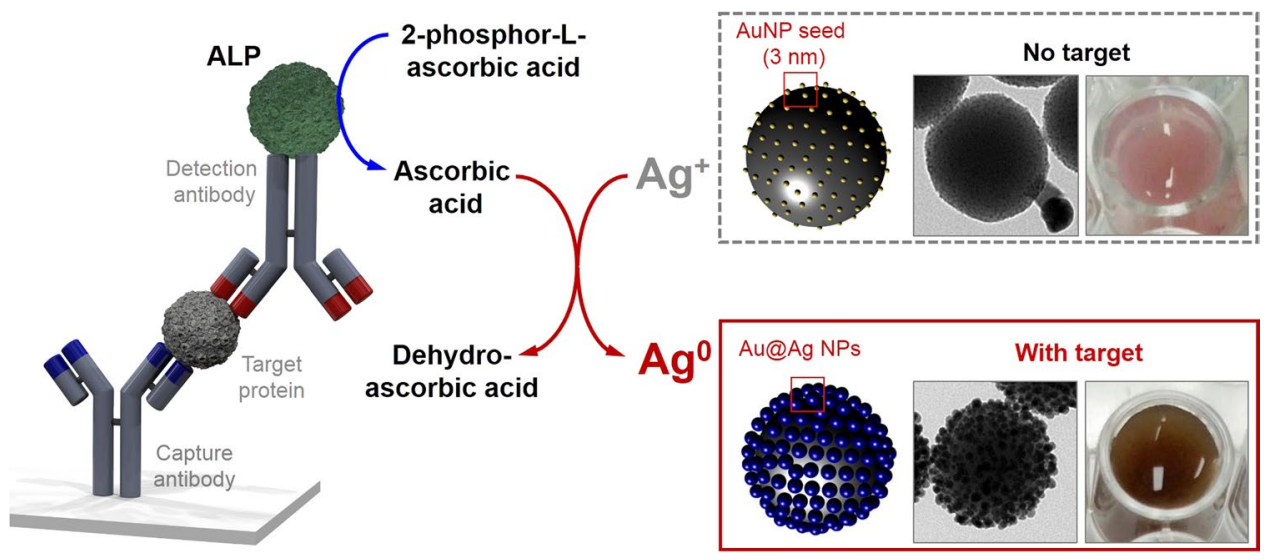

Figure 1. Schematic representation of enzyme-catalyzed Ag growth on Au nanoparticle-assembled structures. In the presence of target IgG, the immune complex $A b_{1}-I g G-A b_{2}$, which contains alkaline phosphatase (AP), triggers enzyme-catalyzed conversion of 2-phospho-L-ascorbic acid to ascorbic acid. The ascorbic acid reduces $\mathrm{AgNO}_{3}$ to Ag metal which can be deposited on the surface of AuNPs on silica NPs. As Ag deposition on the surface of $\mathrm{SiO}_{2} @$ Au results in strong absorbance, significant colorimetric changes can be observed, allowing for highly sensitive colorimetric immunoassay.

Bimetallic Au-Ag NPs can provide an alternative solution as localized surface plasmon resonance (LSPR) of $\mathrm{Au}-\mathrm{Ag}$ NPs can enhance the strength of electromagnetic field around NP surface. In addition, Au-Ag alloy NPs offer several distinctive advantages: 1) improved plasmonic efficiency; 2) higher refractive index sensitivities exclusively from $\mathrm{Ag}$; and 3) long-term stability and biocompatibility from $\mathrm{Au}^{37}$. In particular, the optical properties of Au-Ag NPs can be tuned by manipulating the growth of Ag shell thickness on Au NPs ${ }^{38-42}$. Recently, assembly of $\mathrm{Au}$ and/or Ag NPs on a silica NP template was reported by several groups ${ }^{41,43-53}$. Higher LSPR was observed from Au and/or Ag NPs of controlled density, in which the gaps between the NPs were adjusted, than from either Au or Ag NP alone . $^{4}$.

In this study, we have controlled Ag deposition on AuNP surface, assembled on silica NPs by an enzyme-catalyzed reaction. Results showed amplified ELISA signals and improvement in the sensitivity of colorimetric immunoassay. In our model study, IgG concentration was determined from color change, and absorbance intensity was detected by the formation of Ag shells on the surface of Au NPs. The plasmonic immunoassay showed a significantly linear relationship between absorbance and logarithm of IgG concentration with thousand folds higher sensitivity than that of any conventional colorimetric immunoassay.

\section{Results and Discussion}

The plasmonic-based colorimetric immunoassay (Fig. 1) caused a strong colorimetric change by combining two features - enzyme-mediated amplification of $\mathrm{Ag}^{+}$ion reduction and promotion of $\mathrm{Ag}$ growth on the assembled AuNP structure $\left(\mathrm{SiO}_{2} @ \mathrm{Au} @ \mathrm{Ag}\right)$. As a model study, rabbit IgG (antigen) was utilized as a target for the immunoassay. Polyclonal goat anti-rabbit IgG (capture antibody, Ab1), which was used as a platform to capture the rabbit IgG, was immobilized on a 96-well microplate. Subsequently, polyclonal AP-conjugated goat anti-rabbit IgG (detection antibody, $\mathrm{Ab}_{2}$ ) was used as a tracer antibody in the plasmonic-based colorimetric immunoassay. In the presence of the target IgG, the immune complex of $A b_{1}-I g G-A b_{2}$, which contained alkaline phosphatase (AP), was able to trigger enzyme-catalyzed conversion of 2-phospho-L-ascorbic acid to ascorbic acid. The produced ascorbic acid reduced $\mathrm{AgNO}_{3}$ to $\mathrm{Ag}$ metal, which was deposited on the surface of AuNPs on silica NPs ( $\mathrm{SiO}_{2} @$ $\mathrm{Au}$ ). The deposition shifted the ultraviolet-visible (UV-Vis) spectra towards $430 \mathrm{~nm}$, which coincided with the absorbance peak of Ag. The shift in absorbance was proportional to the IgG concentration in the sample, which was quantified by monitoring the intensity of absorbance at $430 \mathrm{~nm}$.

One prerequisite for developing effective plasmonic-based colorimetric immunoassay is the coating of $\mathrm{Ag}$ metal on the $\mathrm{SiO}_{2} @$ Au surface in the presence of the ascorbic acid reduction system. To demonstrate this, $\mathrm{SiO}_{2} @$ $\mathrm{Au}$ was prepared by immobilizing Au NPs on aminated silica NPs (ca. $150 \mathrm{~nm}$ in diameter). Colloidal AuNPs $(2-3 \mathrm{~nm})$ were prepared by reducing $\mathrm{HAuCl}_{4}$ with tetrakis (hydroxymethyl) phosphonium chloride (THPC) according to the method reported by Duff et al. with slight modification ${ }^{55}$. The AuNPs were immobilized on the aminated silica NPs by gentle shaking. Figure S1 shows the assembly of ca 2,300 AuNPs on the surface of the aminated silica NPs. Selective formation of Ag shells on the surface of Au NPs on silica occurred when $\mathrm{AgNO}_{3}$ were reduced in the presence of ascorbic acid and polyvinylpyrrolidone (PVP). The thickness of AgNPs was adjusted by the ascorbic acid concentration in the solution. $\mathrm{AgNO}_{3}$ concentration was maintained at $10 \mathrm{mM}$, whereas that of ascorbic acid varied from 2 to $100 \mu \mathrm{M}$. The amount of $\mathrm{SiO}_{2} @ \mathrm{AuNPs}$ was fixed at $100 \mu \mathrm{g}$.

Typical transmission electron microscopy (TEM) images are shown in Figs 2A and S2. The size of Au@AgNPs on the surface of the silica NPs increased with the concentration of ascorbic acid from 2 to $100 \mu \mathrm{M}$. UV-Vis spectra of the resulting $\mathrm{SiO}_{2} @ \mathrm{Au} @ \mathrm{Ag}$ solution are shown in Fig. 2, which match well with their corresponding TEM images. Owing to low absorbance of the 3 nm-sized AuNPs, $\mathrm{SiO}_{2} @ A$ AuNPs did not show the typical UV peak of AuNPs at $500-520 \mathrm{~nm}^{55}$. A broad plasmonic adsorption peak was observed between $320 \mathrm{~nm}$ and $700 \mathrm{~nm}$, with its maximum at ca. $430 \mathrm{~nm}$, after deposition of $\mathrm{Ag}$ metal on $\mathrm{SiO}_{2} @ \mathrm{AuNPs}$, which can be attributed to the formation 
A
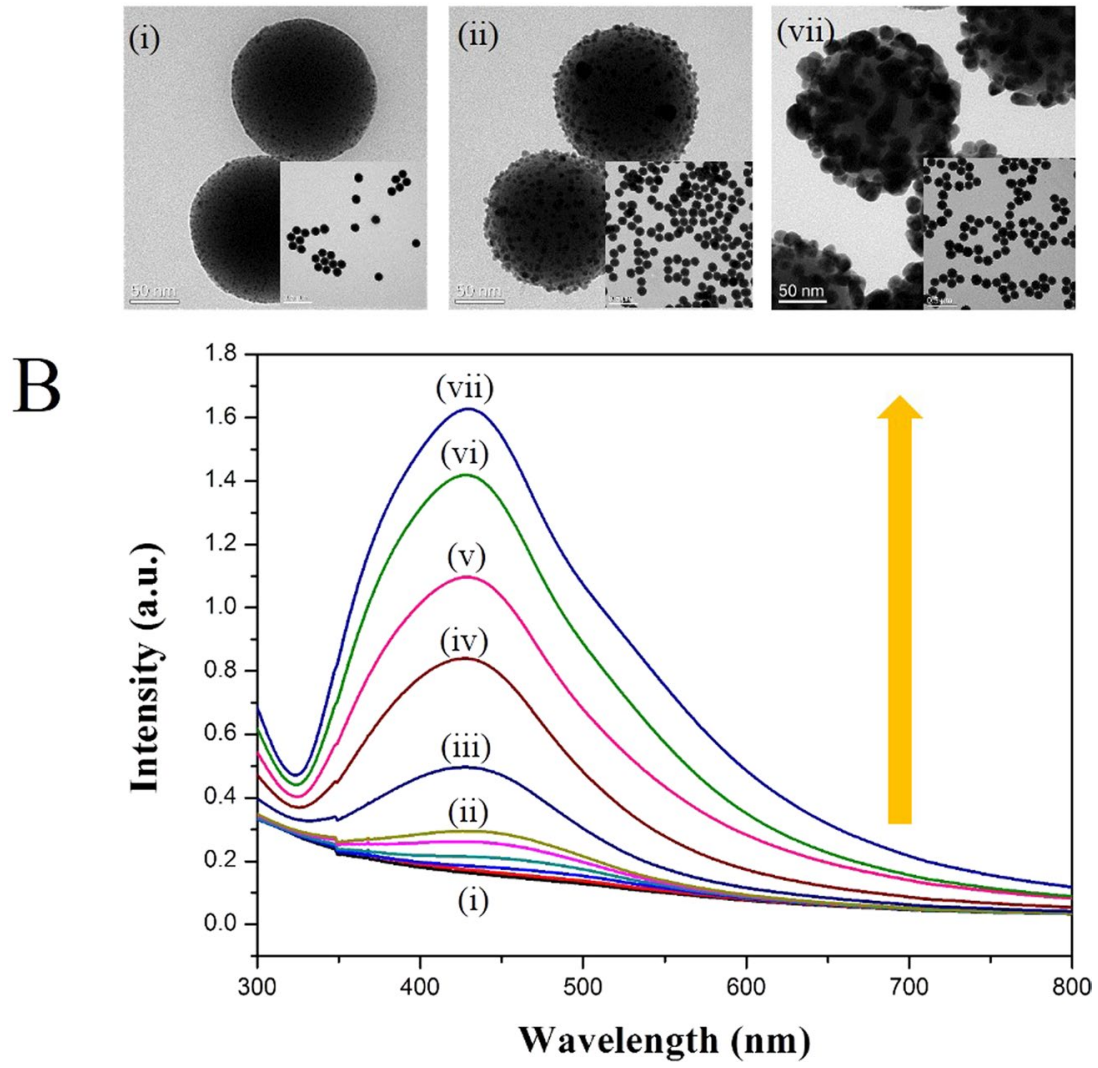

Figure 2. (A) Transmission electron microscopy (TEM) images and (B) optical properties of $\mathrm{SiO}_{2} @ \mathrm{Au} @ \mathrm{Ag}$ solution at different concentrations of ascorbic acid: (i) $0 \mu \mathrm{M}$, (ii) $10 \mu \mathrm{M}$, (iii) $20 \mu \mathrm{M}$, (iv) $40 \mu \mathrm{M}$, (v) $60 \mu \mathrm{M}$, (vi) $80 \mu \mathrm{M}$, and (vii) $100 \mu \mathrm{M}$. Measurement values for $\mathrm{SiO}_{2} @ \mathrm{Au}$ and $\mathrm{AgNO}_{3}$ are $100 \mu \mathrm{g}$ and $1 \mathrm{nmol}$, respectively.

of Ag shells on the surface of $\mathrm{SiO}_{2} @ \mathrm{Au} \mathrm{NPs}^{56-58}$. In addition, the intensities of peaks at $430 \mathrm{~nm}(\mathrm{Ag})$ and $510 \mathrm{~nm}$ $\mathrm{Au})$ were proportional to the concentration of ascorbic acid across a broad range $(2,4,6,8,10,20,40,60,80$, and $100 \mu \mathrm{M}$ ), indicating proportional growth of the Ag shells on $\mathrm{SiO}_{2} @ \mathrm{Au} @ \mathrm{Ag}\left(\right.$ Figs 2B and S3) ${ }^{58,59}$. The appearance of a new absorbance peak of $\mathrm{SiO}_{2} @ \mathrm{Au} @ \mathrm{Ag}$ at $430 \mathrm{~nm}$ could be explained by the positive effect of ascorbic acid-induced $\mathrm{Ag}$ shell coating on the $\mathrm{SiO}_{2} @ \mathrm{Au}$ surface.

To investigate the functionality of the plasmonic-based colorimetric immunoassay, AP-conjugated goat anti-rabbit IgG was utilized as the detection antibody. First, we determined the correlation in optical properties between the immunocomplex $\left(\mathrm{Ab}_{1}, \mathrm{Ab}_{2}\right.$ and $\left.\mathrm{IgG}\right)$ and 2-phospho-L-ascorbic acid concentration (Fig. S4). Three sets of experiments were conducted with varying concentrations of 2-phospho-L-ascorbic acid (up to $16 \mathrm{mM}$ ). As shown in Figure $S 4$ (a, top), the wells in the top row were incubated with $\mathrm{Ab}_{2}$, in the middle row with IgG, and the bottom row with both IgG and $\mathrm{Ab}_{2}$. In the absence of either IgG or $\mathrm{Ab}_{2}$, the resulting $\mathrm{SiO}_{2} @ \mathrm{Au} @ A g$ solution showed no significant changes in color regardless of the 2-phospho-L-ascorbic acid concentration. In contrast, the colors of the resulting $\mathrm{SiO}_{2} @ \mathrm{Au} @ \mathrm{Ag}$ containing IgG and $\mathrm{Ab}_{2}$ significantly changed from varying degrees of yellow to deep brown, indicating growth of $\mathrm{Ag}$ on the surface of $\mathrm{SiO}_{2} @ \mathrm{Au}$ to generate $\mathrm{SiO}_{2} @ \mathrm{Au} @ \mathrm{Ag}$. The intensity of the $\mathrm{SiO}_{2} @ A u @ A g$ absorbance increased with 2-phospho-L-ascorbic acid concentration and achieved its highest value at $12 \mathrm{mM}$ (Fig. S4b,c). The increase in absorption intensity in our assay can be attributed to the enzyme-based catalytic reaction of AP conjugated with $\mathrm{Ab}_{2}$.

We also investigated the effect of blocking duration with bovine serum albumin (BSA) on the absorbance signal of $\mathrm{SiO}_{2} @ \mathrm{Au} @ \mathrm{Ag}$. The microplate was incubated with 1\% BSA to prevent nonspecific adsorption and the results are shown in Fig. S5. The background signal of SiO $@ @ A u @ A g$ decreased slightly from $0.290 \pm 0.042$ to $0.232 \pm 0.035$ after incubating with BSA for 30 minutes. Longer incubation time with BSA did not improve this prevention effect but decreased the absorbance intensity of IgG (incubation of 120 minutes).

Next, we investigated the effect of enzymatic incubation time on absorbance intensity (Fig. S6). The absorbance intensity of the $\mathrm{SiO}_{2} @ \mathrm{Au} @ \mathrm{Ag}$ solution was proportional to the incubation time and attained its highest value at 40 minutes. This indicates that the enzyme AP was able to efficiently catalyze and transfer 2-phospho-L-ascorbic acid to L-ascorbic acid in our assay. In addition, the seed amount of $\mathrm{SiO}_{2} @ \mathrm{Au}$ can be a critical factor for enhancing the absorbance properties of $\mathrm{SiO}_{2} @ \mathrm{Au} @ \mathrm{Ag}$. Subsequently, we studied the effect of $\mathrm{SiO}_{2} @ \mathrm{Au}$ loading amount on the growth of $\mathrm{SiO}_{2} @ \mathrm{Au} @ \mathrm{Au}$. The solution color changed from dark grey to light yellow with increase in the concentration of $\mathrm{SiO}_{2} @ \mathrm{Au}$ from $1 \mathrm{mg} / \mathrm{mL}$ to $5 \mathrm{mg} / \mathrm{mL}$. The absorbance intensity of $\mathrm{SiO}_{2} @ \mathrm{Au} @ A g$ increased 

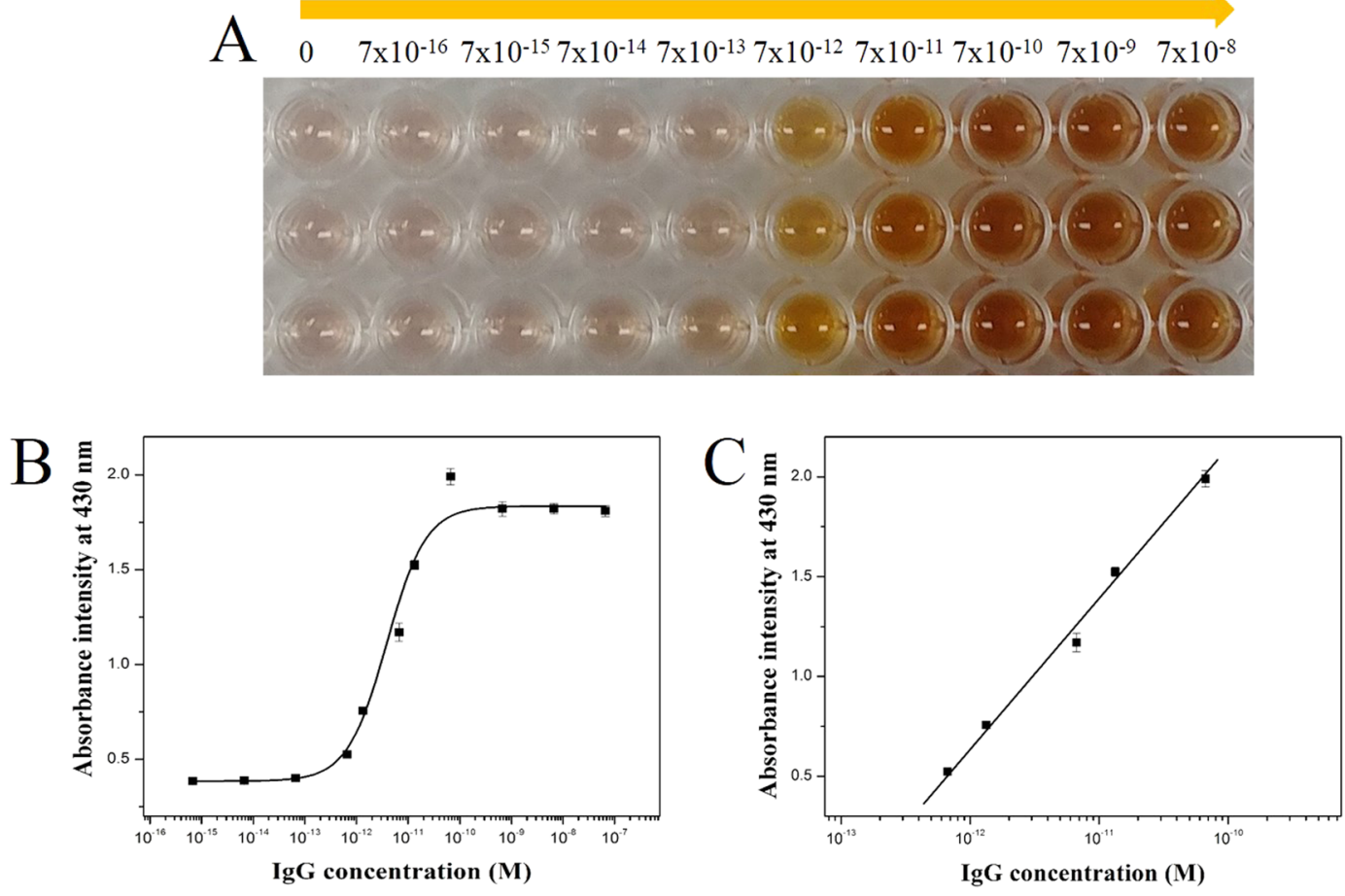

Figure 3. (A) Color change plot, (B) the corresponding UV-Vis absorbance intensity plot, and (C) dynamic range of plasmonic enzyme-linked immunosorbent assay with different concentrations of IgG in the range of $7 \times 10^{-16}$ to $7 \times 10^{-8} \mathrm{M}$. Inset shows the limit of detection of plasmonic-based colorimetric immunoassay. Error bars show the standard deviation of three independent measurements.

with $\mathrm{SiO}_{2} @ \mathrm{Au}$ concentration. The $\mathrm{SiO}_{2} @ \mathrm{Au} @ \mathrm{Ag}$ synthesized at $4 \mathrm{mg} / \mathrm{mL}$ showed the highest value of absorbance intensity as shown in Fig. S7.

To reduce the time required for performing an ELISA immunoassay, we attempted to combine the enzyme reaction and ascorbic acid-induced Ag NP deposition into one step, hereafter referred to as the "combination" step. In contrast, the term "separation" indicates that the enzyme reaction and ascorbic acid-induced Ag NP deposition were separated into two steps. The IgG concentration was fixed at $4 \times 10^{-10} \mathrm{M}$. As a result, the absorbance intensity of the $\mathrm{SiO}_{2} @ A u @ A g$ in "combination" technique decreased to $25 \%$ compared to that in "separation technique (Fig. S8). For comparing the combination and separation techniques, we changed IgG concentration from $7 \times 10^{-16}$ to $7 \times 10^{-9} \mathrm{M}$. The absorbance signal was not significantly different at high IgG concentration because the enzyme in solution was sufficiently saturated to catalyze the further conversion of all 2-phospho-L-ascorbic acid to L-ascorbic acid. The absorbance signal of the combination sample increased gradually when the IgG concentration ranged from of $4 \times 10^{-11}$ to $7 \times 10^{-10} \mathrm{M}$ because of the gradual conversion of 2-phospho-L-ascorbic acid to L-ascorbic acid. In contrast, the disposable availability of L-ascorbic acid in the enzyme reaction step resulted in a sharp increase in absorbance signal in the separation method. Furthermore, we compared the effect of $\mathrm{SiO}_{2} @$ Au concentration on the resulting absorbance intensity using this immunoassay. The absorbance signal was not significantly different at high IgG concentration because the enzyme in solution was amply saturated to support further conversion of all 2-phospho-L-ascorbic acid to L-ascorbic acid. The absorbance signal of the "combination" sample increased gradually when the IgG concentration ranged from $4 \times 10^{-11}$ to $7 \times 10^{-10} \mathrm{M}$ because of the gradual conversion of 2 -phospho-L-ascorbic acid to L-ascorbic acid. In contrast, the presence of L-ascorbic acid in the previous adjacent enzyme reaction step caused a sharp increase in absorbance signal in the "separation" method. Furthermore, the effect of $\mathrm{SiO}_{2} @ \mathrm{Au}$ concentration on the resulting absorbance intensity was investigated. The absorbance intensity of $\mathrm{SiO}_{2} @ \mathrm{Au} @ \mathrm{Ag}$ in the "combination" method increased gradually with the logarithm of IgG concentration and ranged from $7 \times 10^{-11} \mathrm{M}$ to $7 \times 10^{-9} \mathrm{M}$. On the contrary, the absorbance intensity of $\mathrm{SiO}_{2} @ \mathrm{Au} @ \mathrm{Ag}$ in the "separation" method increased sharply with the logarithm of IgG concentration and ranged from $7 \times 10^{-13} \mathrm{M}$ to $7 \times 10^{-11} \mathrm{M}$ because of the presence of higher concentration of L-ascorbic acid in the enzyme reaction step as mentioned previously. From these results, we concluded that the gradual increase in the absorbance intensity of the "combination" is possibly due to the partial inhibitory effect of $\mathrm{Ag}^{+}$ions on AP activity. The limit of detection (LOD) and limit of quantification of the "separation" method were $0.02 \mathrm{ng} / \mathrm{mL}$ and $0.69 \mathrm{ng} / \mathrm{mL}$, respectively. In contrast, the LOD and LOQ of the "combination" method were 0.22 $\mathrm{ng} / \mathrm{mL}$ and $0.72 \mathrm{ng} / \mathrm{mL}$.

The absorbance intensity of the $\mathrm{SiO}_{2} @ \mathrm{Au} @ \mathrm{Ag}$ solution at various IgG concentrations was obtained after optimizing the assay conditions. Figure 3A depicts the colors of the $\mathrm{SiO}_{2} @ \mathrm{Au} @ \mathrm{Ag}$ solutions after enzyme-induced colorimetric enhancement. The solution color showed a dramatic change from light pink to deep brown when the concentration of IgG increased from $7 \times 10^{-16}$ to $7 \times 10^{-7} \mathrm{M}$, which implied that ascorbic acid was produced from 
2-phospho-L-ascorbic acid in the solution by anti-rabbit IgG-conjugated AP, which was able to reduce $\mathrm{Ag}^{+}$ion to Ag metal on the surface of $\mathrm{SiO}_{2} @ A u$ to generate $\mathrm{SiO}_{2} @ \mathrm{Au} @ \mathrm{Ag}$. The absorbance intensities of the reaction samples containing $\mathrm{SiO}_{2} @ \mathrm{Au} @ \mathrm{Ag}$ are depicted in Fig. 3B. The absorbance intensity at $430 \mathrm{~nm}$ exhibited a slight change when the concentration of IgG was below $7 \times 10^{-14} \mathrm{M}$. Insufficient amounts of $\mathrm{Ab}_{2}$ might have resulted in negligible ascorbic acid production in the solution, causing low levels of Ag metal deposition on the surface of SiO2@ $\mathrm{Au}$. On the contrary, IgG concentration $>7 \times 10^{-13} \mathrm{M}$ showed significant absorbance intensity of $\mathrm{SiO}_{2} @ \mathrm{Au} @ \mathrm{Ag}$ at $430 \mathrm{~nm}$. The absorbance intensity increased significantly with IgG concentration because of the growth of Ag on the surface of $\mathrm{SiO}_{2} @ \mathrm{Au}$ (Fig. 3B). A logistic curve-fitting was utilized for calibration. A logistic curve relationship between the absorbance and the logarithm of IgG concentration from $7 \times 10^{-13} \mathrm{M}$ to $7 \times 10^{-11} \mathrm{M}$ could be fitted onto the experimental data. The LOD was $1.4 \times 10^{-13} \mathrm{M}(0.021 \mathrm{ng} / \mathrm{mL})$. The relative standard deviation of our samples ranged from 0.5 to $9.6 \%$. The detection limit of our technique showed values that were hundred folds higher than that of conventional ELISA. The LOD of our $\mathrm{SiO}_{2} @ A u$-based method was 10-fold lower than that of Ag NP-based plasmonic ELISA ${ }^{30}$.

We determined the recovery to validate our method for detecting IgG concentration. We prepared two IgG samples of $3.34 \times 10^{-10} \mathrm{M}$ and $6.67 \times 10^{-10} \mathrm{M}$ concentration and used the logistic fitting curve to calculate the IgG concentration in the sample. Results showed that the IgG concentrations obtained were $3.56 \pm 0.03 \times 10^{-10}$ and $6.15 \pm 0.03 \times 10^{-10}$; which correspond to $106.8 \pm 1.0 \%$ and $92.2 \pm 1.6 \%$ recovery, respectively. Therefore, the average recovery is $99.5 \%$.

\section{Conclusion}

We have developed a novel plasmonic colorimetric immunoassay for detecting target proteins with a detection limit of $1.4 \times 10^{-13} \mathrm{M}$. This assay features a dynamic range that is hundred times higher than that of the traditional enzyme-based colorimetric immunoassay, which was achieved by utilizing an AP-conjugated detection antibody to catalyze the conversion of 2-phospho-L-ascorbic acid to ascorbic acid. The presence of ascorbic acid induced the reduction of $\mathrm{Ag}^{+}$ion to $\mathrm{Ag}$ metal on the surface of $\mathrm{SiO}_{2} @ \mathrm{Au}$, which enhanced the absorbance peak at $430 \mathrm{~nm}$. As a result, the absorbance intensity of the $\mathrm{SiO}_{2} @ \mathrm{Au} @ \mathrm{Ag}$ was linearly proportional to the logarithm of IgG concentration in the range from $7 \times 10^{-13} \mathrm{M}$ to $7 \times 10^{-11} \mathrm{M}$. Our plasmonic colorimetric immunoassay is highly sensitive and covers a wide dynamic range. Therefore, it can be used for in vitro diagnostics for the detection of target proteins with the naked eye.

\section{Methods}

Materials. Tetraethylorthosilicate (TEOS), 3-aminopropyltriethoxysilane (APTS), silver nitrate $\left(\mathrm{AgNO}_{3}\right)$, Tetrakis (hydroxymethyl) phosphonium chloride (THPC), gold (III) chloride trihydrate $\left(\mathrm{HAuCl}_{4}\right)$, ascorbic acid (AA), polyvinylpyrrolidone (PVP), PBS buffer $\mathrm{pH} 7.4$ tablet, bicarbonate buffer $\mathrm{pH}$ 8.5, Tween 20, 2-phospho-L-ascorbic acid, anti-rabbit IgG produced in goat (R2004), IgG from rabbit serum (I5006), anti-rabbit IgG-conjugated alkaline phosphatase antibody produced in goat (A3687), and anti-PSA were purchased from Sigma-Aldrich (St. Louis, MO, USA) and used without further purification. Ethyl alcohol (EtOH) and aqueous ammonium hydroxide $\left(\mathrm{NH}_{4} \mathrm{OH}, 27 \%\right)$ were purchased from Daejung (Siheung, Korea). F96 Maxisorp NuncImmuno microplate was purchased from Thermo Fisher Scientific (Roskilde, Denmark).

Preparation of Au NPs assembled silica nanoparticles ( $\mathrm{SiO}_{2} @ A u$ NPs). Approximately 150 $n$ m-sized silica NPs were prepared using Stöber's method ${ }^{60}$. The surface of the aminated silica NPs were modified by amino groups using APTS and a previous method ${ }^{56,57}$. The colloidal Au NPs were prepared by reducing $\mathrm{AuCl} 3$ using THPC. THPC-capped Au NPs were prepared by the method reported by Duff et al ${ }^{55,57}$. Au NPs ( $1 \mathrm{mM}$, $10 \mathrm{~mL}$ ) were modified on the surface of aminated $\mathrm{SiO} 2$ solution $(1 \mathrm{mg} / \mathrm{mL}, 1 \mathrm{~mL})$ by mixing and incubating them in a shaker overnight ${ }^{50}$. Au NP-embedded silica NPs were obtained by centrifugation and washed several times with EtOH to remove unbound Au NPs. The resulting $\mathrm{SiO}_{2} @ \mathrm{Au}$ NPs were redispersed in absolute EtOH to obtain $1 \mathrm{mg} / \mathrm{mLSiO}_{2} @ \mathrm{Au}$ NPs solution ${ }^{56,57}$.

Preparation of $\mathrm{SiO}_{2} @ \mathrm{Au} @ A g$ NPs. Au-Ag core-shell NPs were prepared in an aqueous medium by reducing and depositing Ag source with ascorbic acid on gold NPs in the presence of PVP. Briefly, $100 \mu \mathrm{S} \mathrm{SiO}_{2} @$ Au NPs $(100 \mu \mathrm{L})$ were dispersed in $0.7 \mathrm{~mL}$ PVP $(1 \mathrm{mg} / \mathrm{mL}) . \mathrm{AgNO}_{3}(10 \mathrm{mM}, 100 \mu \mathrm{L})$ was added to the solution, followed by the addition of $10 \mathrm{mM}$ ascorbic acid $(100 \mu \mathrm{L})$. This solution was incubated for $1 \mathrm{~h}$ to reduce $\mathrm{Ag}^{+}$ion to Ag metal. The resulting $\mathrm{SiO}_{2} @ \mathrm{Au} @ A g$ NPs were obtained by centrifugation at 8,500 rpm for 15 mins and washed several times with EtOH to remove excess reagent. The SiO,@Au@Ag NPs were re-dispersed in $1 \mathrm{~mL}$ absolute $\mathrm{EtOH}^{56,57}$

Procedure for detection of rabbit IgG. One hundred microliters of rabbit anti-IgG solution $(10 \mu \mathrm{g} / \mathrm{mL})$ was immobilized overnight in a 96-well microplate. After washing the microplate thrice with PBS containing $0.1 \%$ Tween 20 (PBST), it was blocked using $300 \mu \mathrm{L}$ of $1 \%$ BSA for 30 minutes to prevent nonspecific adsorption. Then, rabbit IgG of various concentrations $(100 \mu \mathrm{L})$ were injected into the microplate and incubated at $37^{\circ} \mathrm{C}$ for $1 \mathrm{~h}$ for antibody-antigen interaction, followed by rinsing each well thrice with PBST. Next, AP conjugated anti-rabbit IgG $(100 \mu \mathrm{L})$ was added to each well and incubated at $37^{\circ} \mathrm{C}$ for 40 minutes, followed by washing with PBST.

One hundred microliters of 2-phospho-L-ascorbic acid (substrate) in a bicarbonate buffer ( $\mathrm{pH} 8.5), 100 \mu \mathrm{L}$ of $\mathrm{SiO}_{2} @ \mathrm{Au}(1 \mathrm{mg} / \mathrm{mL})$, and $100 \mu \mathrm{L}$ of $10 \mathrm{mM} \mathrm{AgNO}_{3}$ in PVP $(1 \mathrm{mg} / \mathrm{mL})$ were simultaneously injected into the microplate and incubated at room temperature for 30 minutes. The prepared sample was diluted 10 times and its UV-Vis absorption spectra at $430 \mathrm{~nm}$ were measured. 


\section{References}

1. Hu, W. et al. Graphene oxide-enabled tandem signal amplification for sensitive SPRi immunoassay in serum. Chem. Commun. 50, 2133-2135 (2014).

2. Tang, L., Casas, J. \& Venkataramasubramani, M. Magnetic Nanoparticle Mediated Enhancement of Localized Surface Plasmon Resonance for Ultrasensitive Bioanalytical Assay in Human Blood Plasma. Anal. Chem. 85, 1431-1439 (2013).

3. Tang, D., Zhang, B., Tang, J., Hou, L. \& Chen, G. Displacement-type Quartz Crystal Microbalance Immunosensing Platform for Ultrasensitive Monitoring of Small Molecular Toxins. Anal. Chem. 85, 6958-6966 (2013).

4. Chon, H. et al. SERS-based competitive immunoassay of troponin I and CK-MB markers for early diagnosis of acute myocardial infarction. Chem. Commun. 50, 1058-1060 (2014).

5. Malashikhina, N., Garai-Ibabe, G. \& Pavlov, V. Unconventional Application of Conventional Enzymatic Substrate: First Fluorogenic Immunoassay Based on Enzymatic Formation of Quantum Dots. Anal. Chem. 85, 6866-6870 (2013).

6. Qiu, Z., Shu, J. \& Tang, D. Bioresponsive Release System for Visual Fluorescence Detection of Carcinoembryonic Antigen from Mesoporous Silica Nanocontainers Mediated Optical Color on Quantum Dot-Enzyme-Impregnated Paper. Anal. Chem. 89, 5152-5160 (2017).

7. Martić, S., Gabriel, M., Turowec, J. P., Litchfield, D. W. \& Kraatz, H.-B. Versatile Strategy for Biochemical, Electrochemical and Immunoarray Detection of Protein Phosphorylations. JACS 134, 17036-17045 (2012).

8. Zhang, B., Tang, D., Goryacheva, I. Y., Niessner, R. \& Knopp, D. Anodic-Stripping Voltammetric Immunoassay for Ultrasensitive Detection of Low-Abundance Proteins Using Quantum Dot Aggregated Hollow Microspheres. Chemistry - A European Journal 19, 2496-2503 (2013).

9. Qiu, Z., Shu, J. \& Tang, D. Near-Infrared-to-Ultraviolet Light-Mediated Photoelectrochemical Aptasensing Platform for Cancer Biomarker Based on Core-Shell NaYF4:Yb,Tm@TiO2 Upconversion Microrods. Anal. Chem. 90, 1021-1028 (2018).

10. Shu, J. \& Tang, D. Current Advances in Quantum-Dots-Based Photoelectrochemical Immunoassays. Chemistry - An Asian Journal 12, 2780-2789 (2017)

11. Zhang, K., Lv, S., Lin, Z. \& Tang, D. CdS:Mn quantum dot-functionalized g-C3N4 nanohybrids as signal-generation tags for photoelectrochemical immunoassay of prostate specific antigen coupling DNAzyme concatamer with enzymatic biocatalytic precipitation. Biosens. Bioelectron. 95, 34-40 (2017).

12. Lin, Y., Zhou, Q., Tang, D., Niessner, R. \& Knopp, D. Signal-On Photoelectrochemical Immunoassay for Aflatoxin B1 Based on Enzymatic Product-Etching MnO2 Nanosheets for Dissociation of Carbon Dots. Anal. Chem. 89, 5637-5645 (2017).

13. Lin, Y., Zhou, Q. \& Tang, D. Dopamine-Loaded Liposomes for in-Situ Amplified Photoelectrochemical Immunoassay of AFB1 to Enhance Photocurrent of Mn2+-Doped Zn3(OH)2V2O7 Nanobelts. Anal. Chem. 89, 11803-11810 (2017).

14. Liu, W., Cassano, C. L., Xu, X. \& Fan, Z. H. Laminated Paper-Based Analytical Devices (LPAD) with Origami-Enabled Chemiluminescence Immunoassay for Cotinine Detection in Mouse Serum. Anal. Chem. 85, 10270-10276 (2013).

15. Gao, Z., Xu, M., Hou, L., Chen, G. \& Tang, D. Magnetic Bead-Based Reverse Colorimetric Immunoassay Strategy for Sensing Biomolecules. Anal. Chem. 85, 6945-6952 (2013).

16. Lai, W., Tang, D., Zhuang, J., Chen, G. \& Yang, H. Magnetic Bead-Based Enzyme-Chromogenic Substrate System for Ultrasensitive Colorimetric Immunoassay Accompanying Cascade Reaction for Enzymatic Formation of Squaric Acid-Iron(III) Chelate. Anal. Chem. 86, 5061-5068 (2014).

17. Chen, D., Sarikaya, N. A., Gunn, H., Martin, S. W. \& Young, J. D. ELISA Methodology for Detection of Modified Osteoprotegerin in Clinical Studies. Clinical Chemistry 47, 747-749 (2001).

18. Stejskal, D. et al. Proguanylin: development, analytical characterization, and clinical testing of a new ELISA. General physiology and biophysics 26, 62-65 (2007).

19. Wilson, R. M. \& Danishefsky, S. J. A Vision for Vaccines Built from Fully Synthetic Tumor-Associated Antigens: From the Laboratory to the Clinic. JACS 135, 14462-14472 (2013).

20. Wang, S. et al. Micro-a-fluidics ELISA for Rapid CD4 Cell Count at the Point-of-Care. Scientific Reports 4, 3796 (2014).

21. Jiang, W. et al. Simultaneous Determination of 13 Fluoroquinolone and 22 Sulfonamide Residues in Milk by a Dual-Colorimetric Enzyme-Linked Immunosorbent Assay. Anal. Chem. 85, 1995-1999 (2013).

22. Lei, J. \& Ju, H. Signal amplification using functional nanomaterials for biosensing. Chem. Soc. Rev. 41, 2122-2134 (2012).

23. Qu, W., Liu, Y., Liu, D., Wang, Z. \& Jiang, X. Copper-Mediated Amplification Allows Readout of Immunoassays by the Naked Eye. Angewandte Chemie 123, 3504-3507 (2011).

24. Aragay, G., Pino, F. \& Merkoçi, A. Nanomaterials for Sensing and Destroying Pesticides. Chem. Rev. 112, 5317-5338 (2012).

25. Saha, K., Agasti, S. S., Kim, C., Li, X. \& Rotello, V. M. Gold Nanoparticles in Chemical and Biological Sensing. Chem. Rev. 112, 2739-2779 (2012).

26. Swierczewska, M., Liu, G., Lee, S. \& Chen, X. High-sensitivity nanosensors for biomarker detection. Chem. Soc. Rev. 41, 2641-2655 (2012).

27. Perfezou, M., Turner, A. \& Merkoci, A. Cancer detection using nanoparticle-based sensors. Chem. Soc. Rev. 41, 2606-2622 (2012).

28. Vignati, G., Chiecchio, A., Osnaghi, B., Giovanelli, L. \& Meloncelli, C. In Clinical Chemical Laboratory Medicine Vol. 46264 (2008).

29. Gupta, S., Huda, S., Kilpatrick, P. K. \& Velev, O. D. Characterization and Optimization of Gold Nanoparticle-Based Silver-Enhanced Immunoassays. Anal. Chem. 79, 3810-3820 (2007).

30. Xuan, Z. et al. Plasmonic ELISA based on the controlled growth of silver nanoparticles. Nanoscale 8, 17271-17277 (2016).

31. Kulkarni, G. S., Zang, W. \& Zhong, Z. Nanoelectronic Heterodyne Sensor: A New Electronic Sensing Paradigm. Acc. Chem. Res. 49, 2578-2586 (2016).

32. Wang, X., Niessner, R. \& Knopp, D. Controlled growth of immunogold for amplified optical detection of aflatoxin B1. Analyst 140, 1453-1458 (2015).

33. Liu, D. et al. Glucose Oxidase-Catalyzed Growth of Gold Nanoparticles Enables Quantitative Detection of Attomolar Cancer Biomarkers. Anal. Chem. 86, 5800-5806 (2014).

34. Wang, S., Chen, Z., Choo, J. \& Chen, L. Naked-eye sensitive ELISA-like assay based on gold-enhanced peroxidase-like immunogold activity. Analytical and bioanalytical chemistry 408, 1015-1022 (2016).

35. de la Rica, R. \& Stevens, M. M. Plasmonic ELISA for the detection of analytes at ultralow concentrations with the naked eye. Nat. Protocols 8, 1759-1764 (2013).

36. Zhang, Z., Chen, Z., Cheng, F., Zhang, Y. \& Chen, L. Iodine-mediated etching of gold nanorods for plasmonic sensing of dissolved oxygen and salt iodine. Analyst 141, 2955-2961 (2016).

37. Erwin, W. R. et al. Plasmon enhanced water splitting mediated by hybrid bimetallic Au-Ag core-shell nanostructures. Nanoscale 6, 12626-12634 (2014).

38. Wu, Q., Zhang, C. \& Li, F. Preparation of spindle-shape silver core-shell particles. Mater. Lett. 59, 3672-3677 (2005).

39. Jackson, J. B. \& Halas, N. J. Silver Nanoshells: Variations in Morphologies and Optical Properties. J. Phys. Chem. B 105, 2743-2746 (2001).

40. Jackson, J. B. \& Halas, N. J. Surface-enhanced Raman scattering on tunable plasmonic nanoparticle substrates. Proc. Natl. Acad. Sci. USA 101, 17930-17935 (2004).

41. Kim, J.-H., Bryan, W. W. \& Randall Lee, T. Preparation, Characterization, and Optical Properties of Gold, Silver, and Gold-Silver Alloy Nanoshells Having Silica Cores. Langmuir 24, 11147-11152 (2008). 
42. Jiang, Z.-j \& Liu, C.-y Seed-Mediated Growth Technique for the Preparation of a Silver Nanoshell on a Silica Sphere. J. Phys. Chem. B 107, 12411-12415 (2003).

43. Jun, B.-H. et al. Silica Core-based Surface-enhanced Raman Scattering (SERS) Tag: Advances in Multifunctional SERS Nanoprobes for Bioimaging and Targeting of Biomarkers\#. Bull. Korean Chem. Soc. 36, 963-978 (2015).

44. Kang, H. et al. Base Effects on Fabrication of Silver Nanoparticles Embedded Silica Nanocomposite for Surface-Enhanced Raman Scattering (SERS). J. Nanosci. Nanotech. 11, 579-583 (2011).

45. Kang, H. et al. Polymer-Mediated Formation and Assembly of Silver Nanoparticles on Silica Nanospheres for Sensitive SurfaceEnhanced Raman Scattering Detection. ACS Appl. Mater. Interfaces 5, 12804-12810 (2013).

46. Kang, H. et al. One-step synthesis of silver nanoshells with bumps for highly sensitive near-IR SERS nanoprobes. J. Mater. Chem. $B$ 2, 4415-4421 (2014).

47. Chang, H. et al. Ag Shell-Au Satellite Hetero-Nanostructure for Ultra-Sensitive, Reproducible, and Homogeneous NIR SERS Activity. ACS Appl. Mater. Interfaces 6, 11859-11863 (2014).

48. Yang, J.-K. et al. Single-Step and Rapid Growth of Silver Nanoshells as SERS-Active Nanostructures for Label-Free Detection of Pesticides. ACS Appl. Mater. Interfaces 6, (12541-12549 (2014).

49. Wang, K., Zhang, X., Niu, C. \& Wang, Y. Template-Activated Strategy toward One-Step Coating Silica Colloidal Microspheres with Sliver. ACS Appl. Mater. Interfaces 6, 1272-1278 (2014)

50. Westcott, S. L., Oldenburg, S. J., Lee, T. R. \& Halas, N. J. Formation and Adsorption of Clusters of Gold Nanoparticles onto Functionalized Silica Nanoparticle Surfaces. Langmuir 14, 5396-5401 (1998).

51. Xue, J., Wang, C. \& Ma, Z. A facile method to prepare a series of SiO2@Au core/shell structured nanoparticles. Mater. Chem. Phys. 105, 419-425 (2007).

52. Sadtler, B. \& Wei, A. Spherical ensembles of gold nanoparticles on silica: electrostatic and size effects. Chem. Commun., 1604-1605 (2002).

53. 11th Int. Conf. on Miniaturized Systems for Chemistry and Life SciencesPang, S., Yang, T. \& He, L. Review of surface enhanced Raman spectroscopic (SERS) detection of synthetic chemical pesticides. TrAC Trends in Analytical Chemistry 85, Part A, 73-82 (2016).

54. Lee, S. et al. Surface-enhanced Raman scattering imaging of HER2 cancer markers overexpressed in single MCF7 cells using antibody conjugated hollow gold nanospheres. Biosens. Bioelectron. 24, 2260-2263 (2009).

55. Duff, D. G., Baiker, A. \& Edwards, P. P. A new hydrosol of gold clusters. 1. Formation and particle size variation. Langmuir 9 , 2301-2309 (1993).

56. Pham, X.-H. et al. Highly sensitive and reliable SERS probes based on nanogap control of a Au-Ag alloy on silica nanoparticles. RSC Adv. 7, 7015-7021 (2017)

57. Shim, S. et al. Size effect of gold on Ag-coated Au nanoparticle-embedded silica nanospheres. RSC Adv. 6, 48644-48650 (2016).

58. Samal, A. K. et al. Size Tunable Au@Ag Core-Shell Nanoparticles: Synthesis and Surface-Enhanced Raman Scattering Properties. Langmuir 29, 15076-15082 (2013).

59. Bastús, N. G., Comenge, J. \& Puntes, V. Kinetically Controlled Seeded Growth Synthesis of Citrate-Stabilized Gold Nanoparticles of up to $200 \mathrm{~nm}$ : Size Focusing versus Ostwald Ripening. Langmuir 27, 11098-11105 (2011).

60. Stöber, W., Fink, A. \& Bohn, E. Controlled growth of monodisperse silica spheres in the micron size range. J. Colloid Interface Sci. 26, 62-69 (1968)

\section{Acknowledgements}

This research was supported by the KU Research Professor Pro-gram of Konkuk University \& funded by the Korean Health Tech-nology R\&D Project, Ministry of Health \& Welfare (HI17C1264).Consulting service from the Microbial Carbohydrate Resource Bank (MCRB, Seoul, Korea) was kindly appreciated.

\section{Author Contributions}

Xuan-Hung Pham, Bong-Hyun Jun, and Yoon-Sik Lee conceived the idea and designed the experiments. XuanHung Pham, Eunil Hahm, Tae Han Kim, and Hyung-Mo Kim performed the experiments. Xuan-Hung Pham, Eunil Hahm, and Dae Hong Jeong analyzed the data. Xuan-Hung Pham, Sang Hun Lee, and Bong-Hyun Jun wrote the manuscript. Bong-Hyun Jun, Dae Hong Jeong, and Yoon-Sik Lee supervised the research.

\section{Additional Information}

Supplementary information accompanies this paper at https://doi.org/10.1038/s41598-018-24664-w.

Competing Interests: The authors declare no competing interests.

Publisher's note: Springer Nature remains neutral with regard to jurisdictional claims in published maps and institutional affiliations.

Open Access This article is licensed under a Creative Commons Attribution 4.0 International License, which permits use, sharing, adaptation, distribution and reproduction in any medium or format, as long as you give appropriate credit to the original author(s) and the source, provide a link to the Creative Commons license, and indicate if changes were made. The images or other third party material in this article are included in the article's Creative Commons license, unless indicated otherwise in a credit line to the material. If material is not included in the article's Creative Commons license and your intended use is not permitted by statutory regulation or exceeds the permitted use, you will need to obtain permission directly from the copyright holder. To view a copy of this license, visit http://creativecommons.org/licenses/by/4.0/.

(C) The Author(s) 2018 